\title{
DIÁLOGOS COM PAIS E MÃES SEPARADOS: GRUPOS REFLEXIVOS NO SISTEMA DE JUSTIÇA
}

\author{
DIALOGUES WITH SEPARATE FATHERS AND MOTHERS: REFLECTIVE \\ GROUPS IN THE JUSTICE SYSTEM
}

\section{LUCIANA DE OLIVEIRA SILVA ${ }^{1}$}

\section{LUDIMILA REGINA ROSENTHAL CAETANO DE OLIVEIRA ${ }^{1}$ \\ LAURA CRISTINA EIRAS COELHO SOARES ${ }^{1}$}

ROSANA LAZARO RAPIZO $^{2}$

\section{${ }^{1}$ Universidade Federal de Minas Gerais, Belo Horizonte/MG, Brasil}

${ }^{2}$ Universidade do Estado do Rio de Janeiro, Rio de Janeiro/RJ, Brasil
RESUM0: 0 artigo refere-se à experiência em projeto de extensão, desenvolvido em parceria com o Ministério Público, voltado para 0 atendimento de famílias que vivenciam 0 contexto do pós-divórcio litigioso. 0 projeto teve como suporte teórico a Psicologia Jurídica e contempla diversas atividades, dentre elas, a condução de grupos compostos por pais e mães separados que se encontravam em situação de conflito. Os grupos, estruturados como proposta reflexiva, objetivaram a oferta de um espaço de diálogo para esses participantes. Dessa forma, os temas organizados em quatro encontros abordaram os atravessamentos psicológicos e sociais presentes no cotidiano de famílias que buscam auxílio junto ao sistema de justiça: relação conjugal e separação; desafios da divisão entre conjugalidade e parentalidade; exercício da parentalidade e desdobramentos para os filhos. Na análise realizada pelos participantes sobre os grupos foram observados como aspectos relevantes do grupo: o reconhecimento da importância das questões trabalhadas, 0 acesso e a reflexão sobre diferentes pontos de vista, a convivência com outros participantes e 0 reconhecimento de vivências semelhantes. Diante do exposto, sugere-se que a atividade realizada possa adquirir outros contornos teóricos e práticos, a fim de ser aplicada em diferentes espaços de atuação da Psicologia.

PALAVRAS-CHAVE: Extensão universitária; Família; Grupos; Divórcio.
ABSTRACT: The article refers to the extension project experience, developed in partnership with the Public Prosecutor's Office, aimed at the care of families who experience the context of the post-divorce litigation. The project had as theoretical support the Juridical Psychology and it contemplates diverse activities, among them, the conduction of groups composed by separated parents and mothers who were in conflict situation. The groups, structured as a reflexive proposal, aimed at providing a space for dialogue for these participants. Thus, the theme is organized in four meetings dealt with the psychological and social crossings present in the daily life of families who seek help from the justice system: conjugal relationship and separation; challenges of the division between conjugality and parenting; exercise of parenting and effects for the children. In the analysis made by the participants about the groups were observed as relevant aspects of the group: recognition of the importance of the questions worked, access and reflection on different points of view, coexistence with other participants and recognition of similar experiences. In view of the above, it is suggested that the activity carried out can acquire other theoretical and practical aspects, in order to be applied in different spaces of action of Psychology.

KEYWORDS: University extension, family, groups, divorce.
Recebido em: 14/08/2018 Aprovado em: 01/10/2018

\section{INTRODUÇÃO}

O presente trabalho relata a experiência de um projeto de extensão desenvolvido com famílias que vivenciam o contexto do pós-divórcio. As atividades são conduzidas sob a perspectiva da Psicologia Jurídica em diálogo com a Psicologia Social e têm como suporte a reflexão crítica e contextualizada sobre os atravessa- 
mentos psicológicos e sociais presentes no cotidiano das famílias que buscam auxílio no sistema de justiça. O Projeto de extensão intitulado "Diálogos familiares em grupo: construindo caminhos para a convivência familiar após a separação conjugal" é resultado de uma parceria entre a Universidade Federal de Minas Gerais (UFMG) e o Programa de Efetivação de Vínculos Familiares e Parentais (PROEVI) ${ }^{3}$ do Ministério Público do Estado de Minas Gerais.

Atualmente o PROEVI recebe demandas oriundas da Vara da Família e também demandas espontâneas. As solicitações mais frequentes dizem respeito à regulamentação de visitas, estabelecimento de guarda, sendo que alguns pedidos costumam chegar acompanhados de denúncias sobre alienação parental. As famílias encaminhadas ao programa, em geral, apresentam um alto grau de litígio e dificuldades para estabelecer diálogo não apenas entre os ex-cônjuges, mas também com os filhos e com membros das famílias extensas.

Devido à complexidade processual presente nos casos, entende-se que essas famílias encaminhadas ao programa estão imersas no que foi descrito por Oliveira e Brito (2013) como judicialização, isto é, "o movimento de regulação normativa e legal do viver, do qual os sujeitos se apropriam para a resolução dos conflitos" (p. 78). A judicialização também envolve o crescimento de situações levadas ao sistema de justiça que visam à resolução de questões da vida particular e/ou das relações. Esse aspecto judicializante aparece no cenário de pós-separação litigiosa quando as dificuldades encontradas para que a comunicação ocorra desembocam em pedidos judiciais, gerando desgaste em todos os integrantes no decorrer de extensas batalhas judiciais.
O trabalho desenvolvido no PROEVI não gera nenhum documento ou relatório emitido para fins judiciais. $\mathrm{O}$ enfoque do programa reside na tentativa de garantir que as crianças e adolescentes tenham o devido acesso e convivência com ambos os pais e também com suas famílias extensas, preservando assim o direito à convivência familiar. Entre as atividades propostas pela extensão, foi prevista a elaboração e a condução de uma intervenção psicossocial por meio da realização de grupos com pais e mães separados ${ }^{4}$ que se encontravam em situação de conflito após separação conjugal. Os grupos, estruturados e inseridos numa lógica reflexiva, possuem como principal objetivo a oferta de um espaço de diálogo para esses pais e mães, visando à redução dos impasses.

A proposta da intervenção psicossocial utilizando os grupos reflexivos foi construída a partir de duas referências principais e, posteriormente, outros aportes teóricos foram somados. A primeira refere-se à pesquisa desenvolvida por Rapizo e Brito (2014) que relata a condução de "espaços de conversas” (p. 38) em grupos compostos por pais e mães separados e por filhos de pais separados. A segunda referência utilizada para a construção dessa proposta foi a investigação desenvolvida por Brito, Cardoso e Oliveira (2010) com grupos reflexivos compostos por pais e mães divorciados em um contexto de pesquisa acadêmica. De acordo com Sarriera, Silva, Pizzinato, Zago e Meira (2000, p. 32), o principal objetivo de uma intervenção psicossocial é "possibilitar melhores condições humanas e de qualidade de vida". Ao ser aplicado aos grupos, esse tipo de intervenção oferece interação entre os sujeitos, permite o compartilhamento das vivências em comum e também das soluções encontradas pelos parti-
${ }^{3}$ Agradecimentos especiais à equipe responsável pelo PROEVI: Procurador de Justiça Bertoldo Mateus de Oliveira Filho; Promotora Miriam Queiroz Lacerda Costa; Psicóloga Fernanda Cunha Guimarães e Assistente Social Carolina Lopes Arantes Mascarenhas.

${ }^{4}$ No presente texto optou-se por não utilizar o termo pais para indicar a composição dos grupos com pais $\mathrm{e}$ mães. Esta escolha decorre do fato de que podem existir experiências de grupos reflexivos compostos apenas por pais e/ou somente por mães. Desta forma, utilizar a expressão pais e mães separados destaca que 0 grupo era misto. 
cipantes para lidarem com os desafios que estes enfrentam (Neiva, 2010). Beiras e Bronz (2016) apontam que os grupos reflexivos se constituem ainda com espaços de convívio, diálogo, problematização e questionamento, sendo também um espaço de produção individual e coletiva de conhecimento. Desta forma os grupos podem ser vistos como espaços de explicitação de discursos dominantes na cultura sobre os temas que neles circulam, assim como por sua possibilidade de diversidade e produção de novos sentidos (Rapizo, 2017).

Em pesquisa, Rapizo e Brito (2014) verificaram como as conversas do grupo reverberam, podendo influenciar e auxiliar em diálogos estabelecidos com pessoas relacionadas externamente aos participantes do grupo. Outro aspecto considerado para a elaboração dos grupos refere-se ao fato de que essa intervenção permite aos membros fazerem uso não apenas das reflexões que surgem, mas também se tornarem sujeitos ativos nas proposições de novas alternativas para si e para os demais integrantes do grupo.

A ideia de se realizar um grupo com pais e mães separados objetivou a criação de um espaço de diálogo e reflexão acerca das situações que estes vivenciam após a separação. Após a separação, o ex-casal e os membros envolvidos em sua rede familiar podem perder suas referências e demais formas de pertencimento social que compõem a construção de suas identidades (Rapizo, 2012). Os sujeitos, que serão impactados de diferentes maneiras, irão se reestruturar em vários âmbitos de sua vida para lidar com essas mudanças. A inexistência de espaços sociais que acolhem as demandas referentes aos desdobramentos do divórcio contribui para a manutenção da concepção social de que a separa- ção será, necessariamente, conflituosa ou para a banalização do luto que envolve o rompimento conjugal. Esta visão pode, muitas vezes, obstaculizar a busca por alternativas. Diante do exposto, a metodologia dos grupos reflexivos foi escolhida, compreendendo-se que esta cria condições para que: os participantes possam falar sobre suas experiências; manifestem sentimentos em relação à nova configuração familiar e a respeito das mudanças que esse processo promoveu em suas vidas; possibilite que suas relações sejam repensadas durante os encontros e que o próprio grupo possa construir caminhos diante do que é exposto (Acosta, Andrade, \& Bronz, 2004).

O trabalho com grupos reflexivos compostos por pais e mães pode ainda ter efeitos na relação com os filhos dos participantes, pois eles podem ser diretamente afetados pelas dificuldades enfrentadas pelos pais. As novas mudanças na rotina, a perda da convivência ou dos vínculos com um dos genitores e/ou família extensa, a dificuldade por parte dos pais em separar a conjugalidade da parentalidade (Brito, 2007; Brito, Cardoso \& Oliveira, 2010) somadas a todas as vivências singulares de cada filho de um ex-casal podem trazer desafios que se tornam ainda maiores na ausência de um olhar voltado para as necessidades dos filhos com intuito de auxiliá-los nessa trajetória.

O percurso apresentado no presente artigo inicia-se com a fundamentação metodológica da intervenção por meio de grupos reflexivos. Posteriormente, cada encontro realizado é descrito em termos de sua construção e condução, relacionando-o com as discussões e questões que emergiram em articulação com o referencial teórico adotado. Como etapa de avaliação dos grupos, são analisados os dados 
coletados por meio dos formulários de avaliação da intervenção. Cabe esclarecer que esse recurso se configura como uma ferramenta anônima de feedback por escrito adaptada do modelo apresentado por Neiva (2010) a ser utilizado em intervenções psicossociais ${ }^{5}$. Por fim, o presente trabalho apresenta o relato da experiência de extensão aqui detalhada sob o olhar das discentes do curso de graduação em Psicologia que foram as facilitadoras dos grupos reflexivos.

\section{METODOLOGIA DE GRUPOS REFLEXIVOS}

Os grupos são um espaço de compartilhamento de dores, sentimentos, temores e de quebra da solidão (Acosta, Andrade, \& Bronz, 2004). A escolha da terminologia "Grupos reflexivos" se deu pois, durante o trabalho grupal, a maneira como os sujeitos se expressam sobre o que é discutido gera ações que podemos considerar como interventivas, já que à medida que um participante reage ressoa em todos os outros e, também, no grupo. Contudo, cabe ressaltar que o grupo reflexivo não possui caráter psicoterapêutico, apesar de proporcionar um espaço que inclui as subjetividades e os sentimentos, podendo auxiliar na promoção de mudanças dos sujeitos envolvidos (Rapizo \& Brito, 2014). O mesmo ocorre em relação à psicoeducação, visto que o grupo reflexivo não possui caráter psicoeducativo: "um método que fornece informação, suporte, treinamento de habilidades ou uma combinação destes" (Yacubian \& Neto, 2001, p. 103). Desta forma, parte-se daquilo que o grupo não é - nem terapêutico, nem psicoeducativo, nem se trata de pesquisa participativa (Brito, Cardoso, \& Oliveira, 2010) para elucidar que a proposta dessa metodologia é gerar a reflexão e o diálogo entre os pais e mães visando à redução do litígio judicial.

O trabalho desenvolvido está situado em local vinculado ao Sistema de Justiça e, portanto, possui atravessamentos específicos dos efeitos da judicialização da família mesmo que sua participação no PROEVI não esteja vinculada à presença de um processo na Vara de Família. O convite para a participação em um grupo que integra as atividades de Programa do Ministério Público implica um desdobramento para a problemática litigiosa que ganha contornos judiciais. Esse aspecto não pode ser negligenciado e deve ser compreendido como um efeito na postura dos sujeitos durante os encontros e no perfil da família participante. Nesse sentido, apesar de buscar a construção de espaços de diálogo, difere-se da proposta conduzida por Rapizo e Brito (2014) pelo contexto específico no qual são desenvolvidos, além do fato de que não inclui filhos no grupo.

No PROEVI, a família é acompanhada pelo setor psicossocial. Desta forma, a equipe técnica realiza o encaminhamento para os grupos reflexivos de ex-casais que, em sua avaliação e seguindo os critérios estabelecidos pelo projeto de extensão, poderiam se beneficiar dessa modalidade de intervenção. Assim, a seleção dos participantes - realizada conjuntamente com a equipe técnica do PROEVI deve considerar que a família precisa estar em acompanhamento psicossocial, pois a participação no grupo visa à modificação da situação litigiosa sendo fundamental o trabalho específico técnico com a família; a ausência de violência contra a criança ou adolescente, evitando assim que a promoção da convivência seja atravessada

\footnotetext{
5 Para conhecimento do modelo de avaliação da intervenção psicossocial, sugere-se a leitura de Neiva, K. M. C. (2010). 0 que é intervenção psicossocial. In Intervenção psicossocial: aspectos teóricos, metodológicos e experiências práticas (pp. 57-58). São Paulo: Vetor.
} 
pela questão do risco e da proteção; e, por fim, que os integrantes não tenham relato de quadro diagnosticado de sofrimento mental, pois tal situação exigiria manejo diferenciado.

A fim de manter o equilíbrio na dinâmica grupal e intervir com os ex-casais encaminhados, optou-se por trabalhar com dois grupos mistos, ou seja, compostos tanto por homens quanto por mulheres, sendo assegurado que nenhum ex-casal poderia pertencer ao mesmo grupo, tendo em vista que isso restringiria a liberdade dos indivíduos para relatarem suas experiências pessoais e poderia acirrar os conflitos. Outro importante critério utilizado foi a alocação de maneira equilibrada entre os dois grupos de pais/mães apontados como responsáveis por dificultar a convivência dos filhos e com aqueles que se encontravam com a convivência restrita ou obstaculizada pelos primeiros. Dessa forma, objetivou-se estimular o aparecimento de diferentes pontos de vista, bem como a possibilidade de se realizar um exercício empático por parte de todos os participantes.

Cada grupo teve quatro encontros com duração de uma hora e meia e frequência quinzenal, visto que cada semana era destinada para um dos grupos. Todas as temáticas abordadas eram referentes aos desdobramentos da separação conjugal, a saber: relacionamento amoroso e separação conjugal; dificuldades em separar as questões da conjugalidade e da parentalidade; o exercício da parentalidade; e, por último, filhos de pais separados. Os temas foram pré-escolhidos pela equipe tendo como suporte o referencial teórico estudado, porém havia abertura para inclusão de outras questões à medida que os integrantes dos grupos trouxessem. $\mathrm{O}$ envio de convites foi via correio e foram feitos contatos telefônicos para os participantes no intuito de estimulá-los a participarem dos grupos. A apresentação da proposta também poderia ocorrer ao final dos atendimentos psicossociais realizados pela equipe do PROEVI.

$\mathrm{Na}$ condução dos encontros foram utilizados vários recursos, a fim de apresentar as temáticas e fomentar as discussões. Esses materiais são semelhantes àqueles que foram denominados por Beiras e Bronz (2016) como disparadores de conversas, ou seja, atividades realizadas no início dos encontros com o objetivo de estimular o debate acerca do tema proposto para o dia. Para organizar a proposta de cada encontro, foram construídas fichas para cada um dos encontros com pontuações e questionamentos a serem abordados, além de estruturar a ordem e o propósito de utilização de cada material. Cabe ressaltar que esta ferramenta tinha como objetivo guiar as discussões e não limitar ou engessar a forma como estas se desenvolviam durante as reflexões. A sua importância, segundo os autores, reside na capacidade de estimular e delimitar as conversas aos temas dos encontros reflexivos, não devendo servir ou constituir, portanto, em atividades que findem em si mesmas. Os materiais utilizados incluíram: dinâmicas e diversos áudio visuais (cenas de filmes, música, trechos de entrevistas, fotos). Ao início e ao final dos grupos foram entregues aos participantes avaliações acerca de suas expectativas em relação ao grupo, solicitando-se sugestões e feedbacks. A seguir, encontra-se o detalhamento dos materiais utilizados em cada um dos quatro encontros, bem como as principais questões e debates que surgiram em cada um deles, analisadas à luz do suporte teórico escolhido. 
Primeiro Encontro: Relacionamento amoroso e separação conjugal

O primeiro encontro foi estruturado objetivando demarcar um ponto de partida para a criação do espaço de discussão e reflexão sobre o divórcio. Para que fosse possível a formação do grupo, foi necessário estabelecer as regras gerais e a aproximação entre as facilitadoras e os participantes. Utilizou-se uma dinâmica de aquecimento para as apresentações e, em seguida, foram ouvidas as expectativas quanto à participação no grupo. A escolha da temática inicial decorreu de aspecto observado no trabalho com grupos de pais, mães e filhos que vivenciaram o divórcio realizado por Brito, Cardoso e Oliveira (2010). Neste, as autoras mencionam que os ex-casais, a princípio, se expressam quanto suas vivências conjugais e só após esse momento conseguem falar sobre as vivências parentais e como os conflitos conjugais refletiram no exercício parental.

O primeiro assunto trabalhado foi "Relacionamento amoroso e separação conjugal”. Essa temática permitiu aos participantes a oportunidade de relatarem as experiências vividas no processo do pós-divórcio, sendo dividida em três sub-temas: aproximação; separação e apoio dos familiares e amigos; o que fica da relação. No primeiro momento, foi utilizada como recurso de discussão sobre o início do relacionamento a música "Eu me lembro" (Falcão \& Souza, 2013). Os participantes dos dois grupos relataram que no início da relação cria-se uma expectativa muito alta em relação ao parceiro, idealizando uma imagem do outro que, muitas vezes, não corresponde à realidade. Segundo os participantes, conhecer melhor o parceiro, assim como a maior convivência, leva a uma quebra das expectativas e também da imagem previamente cons- truída. Para eles, a frustração com o que era esperado do outro foi se tornando o maior problema para a continuidade da relação, sendo algo decisivo para o fim do relacionamento.

O segundo momento tinha como foco a abordagem da iniciativa da decisão de se separar e a recepção dos familiares com a notícia da separação. Para isso foram utilizadas duas cenas do filme "Amor a toda prova" (Ficarra $\&$ Requa, 2011). A primeira cena ${ }^{6}$ ilustra a decisão do rompimento conjugal e a segunda cena ${ }^{7}$ exemplifica como se dava o rearranjo do círculo social após o divórcio. Cada participante trouxe sua visão sobre a decisão de se separar, não havendo uma regra sobre quem decidiu ou recebeu a notícia. No entanto, falaram sobre os diversos conflitos que vivenciaram durante o processo, relatando brigas, desentendimentos, suspeitas de traição, focando sempre na questão de que o outro cônjuge não era mais aquele que eles conheceram no início do relacionamento. Garcia e Tassara (2003), em seus estudos com mulheres casadas sobre os problemas que cercam o casamento, observaram que:

O transcurso entre o momento da escolha do par e a convivência conjugal possibilita às entrevistadas perceberem características nem sempre observadas na fase do namoro. Entre a idealização - "ele é assim" - e as atitudes adotadas por ele no cotidiano da relação - "eu não sabia que ele era assim" - interagem vários aspectos (individuais, sociais, culturais, entre outros) que delimitam essas expectativas de como deveria ser. (Garcia \& Tassara, 2003, p. 132)

Estas questões foram notadas tanto com as mulheres participantes quanto com os homens, apontando que os
${ }^{6}$ Intervalo de tempo da cena 1: 0'0"36"' até 0'1"'20'"'

${ }^{7}$ Intervalo de tempo da cena 2 00 '16"00'" até 00'16" 50 '", 
${ }^{8}$ Intervalo de tempo da cena do filme Divã (2009): 1'06"30'" até 1'07"'44"' ex-companheiros ao longo do relacionamento não eram mais os mesmos, sendo isso apontado como o principal problema que enfrentaram durante o relacionamento conjugal. Sobre a recepção dos amigos quanto à decisão do divórcio, as mulheres relataram que a maioria dos amigos em comum era vinculada aos parceiros homens. Assim, aparentemente, demonstraram que os homens seguiram com essas amizades após o divórcio e elas não o sentiram com uma perda.

Quanto ao envolvimento dos familiares e dos amigos no desenlace conjugal, Brito et al. (2010), em seu trabalho com grupos de pais e mães separados, notaram que os participantes sentiam necessidade de falar sobre as diferentes dificuldades que o contexto do pós-divórcio trazia em suas vidas. Para eles, amigos e familiares não queriam ouvir sobre o assunto, $o$ que, segundo a autora, tornava árduo o enfrentamento dessas dificuldades para aqueles que se separavam.

$\mathrm{Na}$ condução dos grupos, no que tange à receptividade dos familiares, a maioria dos participantes dessa intervenção mencionou que recebeu todo o apoio e que os conflitos estavam tão intensos que alguns familiares já os incentivaram antes mesmo de tomarem a decisão pela separação. Somente uma mulher disse ter sido pressionada pelos familiares a manter o relacionamento e tentar retomar a relação com o ex-marido e, mesmo depois de alguns anos do divórcio, ainda sente que os familiares não aceitam que ela tenha se separado. $\mathrm{O}$ fato de somente uma das participantes mencionar a resistência familiar em relação ao divórcio pode apontar para uma mudança social no modo como as famílias e a sociedade lidam, atualmente, com a possibilidade de uma separação conjugal.
O terceiro momento teve como foco a reflexão sobre o que ficou da relação e foi exibida a cena ${ }^{8}$ final do filme Divã (Britz et al., 2009), na qual é abordado um diálogo, entre um ex-casal, sobre as vivências positivas da relação conjugal que tiveram, bem como o sentimento de gratidão que ambos compartilharam. Os participantes falaram sobre o aprendizado de não criar expectativas em relação ao outro, não esperar que corresponda ao que desejam e que algumas lembranças ainda ficam marcadas e fazem parte de suas vidas para sempre. Para os integrantes do grupo, o mais importante da relação foi a existência do filho. Para alguns, este representa a marca do laço afetivo que existiu entre eles; para outros, nada de relevante restou do relacionamento, além do filho, o que pode apontar para o litígio em que ainda se encontram. Brito (1997, p. 147) expõe que "uma das dificuldades da separação conjugal quando o casal possui filhos é o fato paradoxal de querer desligar-se de alguém de quem, na verdade, não se poderá desprender totalmente, dada a parentalidade comum". Esse paradoxo frequentemente aparece no contexto dos participantes do grupo reflexivo em questão. Percebe-se que estas pessoas, muito envolvidas no contexto jurídico e na disputa, fazem tentativas de se desligar de alguma forma do ex-cônjuge, seja restringindo a convivência dos filhos ou querendo manter vínculo parental sem manter nenhum contato com o ex-companheiro. No entanto, em ambos os casos, os pais são compelidos a manter algum tipo de contato, mesmo que seja judicialmente, por meio dos processos ou dos acompanhamentos realizados pelo sistema de justiça. 
Segundo encontro: Conjugalidade e Parentalidade

O encontro teve como foco trabalhar a dissociação entre a relação conjugal e parental. Como recurso foi utilizada uma dinâmica na qual os participantes recebiam uma caixa que continha frases que citavam situações que deveriam ser classificadas em relações distintas. Para tal, dois círculos foram dispostos, inicialmente, e eles foram convidados a discriminar as relações de amizade com as de trabalho, sendo em um círculo escrito "Amigos" e em outro "Clientes". Os participantes, então, retiravam das caixas frases como: "Sempre conversamos sobre todo tipo de coisa, não ligamos de jogar conversa fora" ou "Agradá-lo e convencê-lo é meu foco!"; que deveriam identificar e inserir no círculo adequado. Em seguida foram discutidas a identificação dessas relações e a importância de diferenciá-las. No segundo momento da dinâmica, os círculos foram virados, contendo os dizeres "ex-marido/ex-esposa" e "Pai/Mãe". Os participantes repetiram o processo anterior, sendo retiradas da caixa frases como: "Ele não era carinhoso comigo, sei lá, não tinha romance...éramos uma empresa que funcionava bem" ou "Gosto de cuidar de tudo que envolve meu filho, acompanho todas as atividades dele", sendo novamente discutidas a diferença e a importância de se distinguir esses espaços. Após esse momento, foram trazidas frases que misturavam as relações conjugais e parentais, sendo expostas frases como "Se ele era agressivo comigo também será agressivo com meus filhos" ou "Recuso-me a falar com ela, por isso peço para meu filho dar os recados".

Cabe ressaltar que alguns pontos causaram maiores discussões e estra- nhamento no decorrer da dinâmica. Notou-se que as mães que obstaculizavam a convivência entre os filhos e os ex-companheiros tiveram muita dificuldade em separar os lugares em que cada relação ocupava, principalmente o que dizia respeito às posturas masculinas em relação às esposas. Para elas, ser um bom pai estaria ligado a ser um bom marido.

Quanto às situações que exemplificavam relatos de agressividade, para elas, se o homem fosse agressivo com a esposa, com certeza, ele seria agressivo com os filhos Nestes casos, portanto, consideravam importante que houvesse a extensão da medida protetiva $^{9}$ à criança. As questões que diziam respeito às agressões entre os genitores, quando utilizadas como justificativa para evitar o contato destes com os filhos, eram sempre bem aceitas entre as integrantes do grupo, dificultando qualquer perspectiva crítica sobre o assunto.

No segundo grupo, a mesma temática trouxe reflexões quanto às diferenças das relações que são estabelecidas ao longo da vida. Os participantes falaram que os sentimentos e reações que o ex-cônjuge despertava, devido ao relacionamento conflituoso, não seriam similares aos sentimentos que os filhos despertariam. Para um dos integrantes, definir uma pessoa que está agressiva por um dado evento não pode ser algo que determine este comportamento em todos os âmbitos de sua vida.

Cardoso e Brito (2015) esclarecem que a violência doméstica contra a mulher pode muitas vezes estar restrita ao contexto conjugal não se estendendo aos filhos. Para as autoras, a falta de pesquisas específicas sobre a garantia da convivência familiar dos filhos e a aplicação da referida lei geram complicações à manutenção dos
${ }^{9}$ A Lei n. 11.340/2006, conhecida popularmente como Lei Maria da Penha, visa coibir e prevenir crimes de violência doméstica $e$ familiar contra a mulher (Lei n. 11340, 2006). As medidas protetivas previstas por esta, tem como objetivo impedir que 0 suposto agressor tenha contato com a vítima e, alguns casos, com os seus filhos, como determina 0 Art.22 inciso IV da mencionada lei. 
vínculos parentais, principalmente, quando há a medida protetiva ativa. Assim, considerando o público que é acompanhado pelo PROEVI, deve-se considerar válido explorar mais, nos próximos grupos a serem realiza$\operatorname{dos}^{10}$, a temática sobre os efeitos da violência contra a mulher no âmbito conjugal na convivência do pai com os filhos no pós-divórcio.

Outra questão discutida neste encontro, que enfatizava a necessidade da cisão entre parentalidade e conjugalidade, foi a reflexão acerca do lugar em que novos cônjuges ocupariam na vida dos filhos. Neste momento, foi exibido um vídeo veiculado na plataforma Youtube intitulado "Pedido emocionante do padrasto: Quer ser minha filha para sempre?", no qual é apresentada a cena de um casamento real em que o padrasto pede a enteada para ser sua filha para sempre diante de todos os convidados. As reações quanto ao vídeo foram de emoção entre as mães e de incômodo entre os pais. Para as mães que restringiam a convivência, o pai poderia ser substituído por um novo companheiro ou, até mesmo, por um tio ou avô. Um ponto que ressaltavam para justificar a resistência em manter o vínculo paterno foram os comportamentos ditos negligentes do ex-cônjuge com os filhos, buscando desqualificá-lo. Esse fato já foi observado por Brito (2001) em situações de disputa de guarda:

A encenação sobre competências e as depreciações de comportamentos e atitudes tornam-se cena constante, quando em um "teatro de máscaras", testemunhas, fatos presenciados e doenças de crianças

${ }^{10} \mathrm{~A}$ partir desta demanda está sendo avaliado 0 planejamento e a inserção de um quinto encontro que abordará esta temática.
Assim, para as participantes, uma vez que fosse considerado que o pai não era capaz de exercer sua paternidade de maneira adequada, caberia a outra figura masculina exercer esse papel, de forma que a própria criança realizaria esse movimento. Quando discutido sobre a importância de separar os espaços parentais daquele dos novos companheiros, essas mães tiveram muita dificuldade em refletir sobre a importância da não substituição.

Observou-se que quando se trata do pai, a visão da substituição ocorre de maneira espontânea, enquanto que a substituição materna não era cogitada. Soares (2015), em pesquisa realizada com pais e mães recasados após a separação conjugal, constatou que não houve correspondência entre as substituições mãe-madrasta, ou seja, em situações em que o pai se recasava, a mãe não era substituída pela madrasta e, em algumas entrevistas, quando cogitada esta possibilidade, não houve aceitação.

Por outro lado, os pais de ambos os grupos demonstraram certo incômodo em cogitar a substituição parental, colocando-se no lugar daquele que era substituído. Para os participantes, aquele que se propõe a substituir o lugar do pai/mãe não pondera sobre a fragilidade de um vínculo estabelecido dessa forma, pois seu relacionamento com o novo companheiro poderia acabar e a situação em que a criança ficaria exposta seria extremamente delicada. Segundo a vivência de alguns participantes que tiveram padrastos/ madrastas, ou atualmente ocupam esse lugar, é importante respeitar o espaço de cada um na nova relação, não sendo nenhum dos pais passíveis de substituição. Em relação ao papel dos novos cônjuges, Soares (2015) menciona, a partir da análise bibliográfica, a indicação de dois modelos para 
o lugar ocupado por padrastos e madrastas: de substituição em relação aos espaços de pai/mãe ou de perenidade, no qual ocupariam novos lugares preservando os de pai/mãe. Em pesquisa posterior desenvolvida com padrastos e madrastas, a autora levanta outras possibilidades de exercício da padrastalidade/madrastalidade para além da perenidade e substituição, considerando a possibilidade de ausência de laço entre padrastos/madrastas e enteados e também a construção de uma relação extremamente mediada pelo pai/ mãe (Soares, 2013).

Em relação à convivência dos filhos com novos companheiros somente uma mãe, que havia passado por dificuldades com a madrasta do filho, narrou sua resistência inicial, falando sobre o medo que tinha da convivência do filho com a mesma, não por receio em ser substituída, mas pelo mito da madrasta má, também descrito por Soares (2015). Para os genitores que sofriam restrições em sua convivência com os filhos e aqueles que já estavam conseguindo lidar com as questões parentais, intermediadas pelo PROEVI, o modelo de perenidade demonstrava ser o mais coerente com o que gostariam de viver em sua parentalidade.

\section{Terceiro Encontro: Parentalidade}

O principal objetivo do terceiro encontro foi propor uma reflexão sobre como os atravessamentos de gênero afetam o exercício da parentalidade. Foi utilizada uma dinâmica inspirada no artigo "Se vendessem mãe, ninguém comprava pai...” da página Pai Legal ${ }^{11}$ sobre atravessamentos de gênero nas relações de guarda. Assim, foram apresentados dois produtos aos participantes que continham anúncios de características que representavam os papéis maternos e paternos segundo o senso comum. Essa dinâmica gerou vários incômodos para os genitores que buscavam o seu direito à convivência ao serem mostradas as frases que se referiam ao produto mãe. As reações foram de incompreensão e indignação. Para eles, todas as afirmativas poderiam, também, ser aplicadas ao produto pai.

A questão acerca da participação paterna foi muito presente durante as discussões. Observou-se que os pais do grupo desejavam ter o direito de exercer suas responsabilidades parentais, ainda que precisassem recorrer ao judiciário para isto. Logo, para eles, as frases que se referiam à mãe ressoaram como críticas ao lugar do pai no cuidado e convívio com os filhos, dificultando qualquer discussão acerca da problematização destas colocações provenientes do que é propagado socialmente.

O exercício da paternidade de forma mais participativa tem chamado atenção e não por acaso se tornou tema central de um dos encontros propostos. Apesar do movimento de transformação na percepção da figura paterna, a resistência enfrentada por pais que buscam pleno contato com os filhos após a dissolução do laço matrimonial é muito presente. Ao longo desse trabalho realizado com os grupos foi possível observar - por parte dos pais - um movimento muito semelhante ao que foi descrito por Brito et al. (2010, p. 822): "A visão, ainda culturalmente marcante, que atribui às mulheres a primazia no cuidado dos filhos, conduzindo-as frequentemente ao lugar de guardiãs, contribui para solidificar e identificar uma série de questões como próprias de comportamentos femininos".

Alguns pais se expressaram sobre as situações que são socialmente colocadas como lugares da mãe e lugares do 
pai em seu dia a dia. Um dos pais, que tinha a guarda do filho, mencionou um episódio em que precisou levá-lo ao pronto atendimento e, quando foi receber as recomendações a serem realizadas no cuidado do filho, foi solicitado que chamasse a mãe da criança. Esse relato denota a importância das diversas instituições pensarem nessas mudanças familiares. Outra questão trazida durante as discussões foi sobre o quanto as mães se colocam à frente desde o nascimento da criança, afastando-as de qualquer exercício do cuidado. Segundo uma das mães, isso se dava por se sentir na obrigação de exercer esse papel sozinha. Sobre esse ponto, Sousa discorre que:

A tradição patriarcal nas sociedades ocidentais, reforçada pela formação católica, contribuiu ao longo do tempo para a estruturação e definição rígida dos papéis sociais de homens e mulheres. ... Os cuidados com filhos ficaram ao encargo das mulheres uma vez que eram em seu corpo concebidos; já aos homens caberia o sustento econômico do grupo familiar. Estudos recentes revelam como esses papéis, tidos no imaginário social como naturais, permanecem sendo, até hoje, estruturados e reproduzidos nas relações sociais. (Sousa, 2010, p. 61)

Para as mães participantes dos grupos, exercer a função de cuidador principal dos filhos era justificado pelo que chamavam de instinto materno, concepção analisada por Badinter (1985) ao formular sobre o mito do amor materno. Segundo as integrantes do grupo, a mãe, por ter o vínculo com a criança desde a gestação, é biologicamente programada para garantir os cuidados dos filhos. Alguns homens também revelavam concordar que os laços entre mães e filhos eram mais fortes pela mesma questão. De acordo com Sousa (2010), a ideia de que a mulher é biologicamente predisposta a exercer os cuidados infantis foi algo construído histórica e socialmente a partir da necessidade da transformação ocorrida ao longo dos séculos XVII e XVIII para a manutenção do alto índice de mortalidade neonatal da época, sendo este discurso, atualmente, ainda muito presente na sociedade e nas relações familiares. Para a autora, a ideia do primado materno, entrelaçada a outros discursos que discorrem a respeito da figura paterna e a dos filhos, repercute no exercício das relações parentais.

Ainda em relação à postura materna nos cuidados parentais, também foi discutido a respeito da sobrecarga que a mulher acaba assumindo após a maternidade. Uma das mães se manifestou quanto à importância de a mulher não ter que desempenhar sozinha todas as responsabilidades e sobre como é comum que aos pais a paternidade seja algo opcional. De acordo com Sousa (2010), após o nascimento do filho, as mulheres passam a assumir mais uma tarefa, além dos trabalhos domésticos e profissionais, considerando esse acúmulo de atividades como atribuição da mulher. A autora menciona a dificuldade de abrir mão desse lugar materno para o exercício da paternidade, apesar da sobrecarga relatada. Essa postura feminina foi pontuada por muitos pais que a percebem no cotidiano do conflito que vivem, sendo que algumas mães acabam interferindo até mesmo quando estes estão sozinhos com os filhos, por meio de ligações, decidindo a rotina e, até mesmo, se estarão de castigo ou não durante as visitas. Este tipo de interferência foi demonstrado também pelo pai guardião, que mes- 
mo afirmando que buscava manter o convívio do filho com a mãe, esta deixava a desejar nos cuidados do filho, sendo necessário que ele acabasse se posicionando quanto à rotina das visitas maternas. Este controle do guardião nos cuidados exercidos pelo outro genitor é exposto por Brito et al. (2010), ao descrever em seu estudo com grupos de pais e mães separados, as principais queixas paternas quando estão com a criança:

Explicaram que é comum a criança receber uma série de ligações telefônicas da mãe com inúmeras recomendações, sendo que, nesses momentos, acham que aproveitam para conferir se a criança comeu ou se tomou banho, avaliando como os pais estão desempenhando seu papel, o que, segundo entendem, os desqualifica perante os filhos. Ao abordar o assunto, muitas mães relataram que não conseguem se desligar dos filhos, mesmo quando estão com os pais, pois compreendem que devem exercer seu papel de guardiãs durante 24 horas. (Brito, Cardoso, \& Oliveira, 2010, p. 818)

Durante o encontro notou-se que os guardiões tendem a assumir o papel de cuidado de tal maneira que, em muitos momentos, não se sentem confortáveis em compartilhar o lugar com os pais que não possuem a guarda. Outro ponto observado foi que esse comportamento era independente do gênero dos participantes, sendo algo mais ligado à função que os guardiões acabam assumindo de cuidadores principais dos filhos. Tal fato foi também observado por Brito (2002) em sua pesquisa sobre os possíveis impasses no contexto de guarda e visitação, em que a autora conclui: "a constatação da acentuada redução da participação de um dos pais na responsabilidade com a prole após a separação. Afastamento que não ocorria em função do gênero e, sim, pela posição de visitante" (Brito, 2002, p. 10).

\section{Quarto Encontro: Filhos de Pais Separados}

Este encontro buscou proporcionar aos participantes uma reflexão acerca do lugar que os filhos ocupam em meio ao litígio e diante das novas configurações familiares. Para isso foi utilizada a dinâmica "O Casamento da Filha”, de autoria da Profa Dra Rosana Rapizo $^{12}$, que se baseia na encenação de uma família recomposta que se reúne a fim de decidir quanto ao casamento de uma filha de pais separados. Os papéis foram distribuídos aos participantes de acordo com os pontos de dificuldades que estes expuseram durante os encontros, porém a alocação dos personagens é estruturada pela equipe de extensão preocupando-se também em não desestabilizar os sujeitos. Os personagens são: noiva, padrasto, mãe, madrasta e noivo ${ }^{13}$. A dinâmica trabalha com o enredo de um casamento em que a noiva reúne a família para decidir questões organizacionais da cerimônia, considerando o convite, a entrada na cerimônia, os lugares que cada membro irá ocupar durante a celebração e, posteriormente, na distribuição de mesas da recepção. Após cada participante receber uma descrição da situação familiar a partir da ótica do seu personagem, precisa interpretar conforme o membro da família no momento da interação para debater sobre as questões que serão resolvidas pelo grupo.

Em ambos os grupos foi observado o deslocamento dos participantes do seu lugar no conflito para o lugar do seu personagem. Os participan-
${ }^{12}$ Comunicação pessoal.

${ }^{13}$ Na dinâmica original, além desses papéis, existe 0 do filho do padrasto, porém, em função do tamanho dos grupos, optamos por não utilizá-lo. 
tes que foram colocados no papel da noiva expuseram o quanto se sentiram pressionados em escolher entre uma pessoa e outra, sendo que ambas eram extremamente importantes. Eles refletiram que se enquanto adultos encenando se sentiram de tal forma, como a filha se sentiria na mesma situação, sendo este cenário comparado a um cabo de força em que ela seria puxada de um lado para o outro pelos pais. Tal situação é evidenciada por Brito (2007, p. 38), ao mencionar que "com a mudança que se estabelece na configuração familiar após a ruptura conjugal, os filhos podem ser colocados no centro das discórdias".

Quanto à discussão acerca do lugar do pai, foram ressaltadas as questões que o impediam de manter a convivência com os filhos e como o seu espaço no rearranjo familiar é passível de substituição pelo padrasto conforme o caso trabalhado na dinâmica. O participante que representou o pai durante a dinâmica passou a colocar a cargo da noiva (filha) todas as decisões e que seria respeitoso às suas escolhas, mas sempre enfatizando que a mãe e o padrasto o colocavam como dispensável durante a vida da filha. Quando indagado sobre sua interpretação, enfatizou que o que importava era como a filha se relacionava com ele e como ela gostaria que seu casamento fosse. Nota-se, assim, que ao mesmo tempo em que se coloca respeitando as decisões da filha, também se percebeu uma pressão para que a filha reconheça os impedimentos que mãe e padrasto colocavam.

Para os participantes que representaram a mãe, o laço que eles tinham por estarem mais próximos da filha, por terem vivenciando situações em que o pai não estava junto, justificava a forma privilegiada como a mãe se posicionava diante das decisões sobre o casamento da filha. Um ponto percebido foi que este arranjo se dava pelo contexto da guarda unilateral, que coloca o guardião como o principal cuidador e, consequentemente, o genitor não guardião passava a ter que se submeter às escolhas do outro. Este posicionamento foi adotado por um dos participantes, homem, que detinha a guarda, ao demonstrar ter comportamentos e pensamentos semelhantes à mãe da dinâmica, pois era ele quem passava mais tempo com o filho e se via como o cuidador principal, tendo a mãe que aceitar o lugar que era criado para ela a partir da separação. Tal constatação também foi ressaltada por Brito (2002) em pesquisa supramencionada na qual constatou a similaridade do discurso referente às queixas parentais, cada um alocado em sua categoria: guardiões e não guardiões com os filhos.

Após o término da primeira dinâmica, nos dois grupos, cada participante recebeu uma poesia que é um trecho da peça "Depois que meus pais se separaram..., de Jessé Guimarães da Silva e Leila Maria Torraca de Brito, publicada no livro de autoria de Christine Vieira Pereira (2013, pp. 13-14). Após a leitura, iniciou-se a discussão sobre como os pais percebem esse momento para os filhos. Em ambos os grupos foi representativo o fragmento "[e] Outra casa de parente onde o filho é estrangeiro". Os participantes discutiram sobre como os filhos, por não terem contato frequente com seus familiares da linhagem do não guardião, eram percebidos dessa forma tanto pelos familiares quanto pelo próprio filho. Neste momento em questão, observou-se que os participantes trouxeram várias reflexões acerca de como percebiam os lugares que os filhos ocupavam em cada família, sendo as situações compreendidas 
por guardiões e não guardiões de maneiras semelhantes a respeito do fato de que os ambientes e as relações eram diversas e que seria muito importante proporcionar ao filho o direito de convivência com os pais e com os demais familiares, o que o faria se sentir acolhido e seguro.

Ao final do encontro foi solicitado aos participantes que elaborassem uma carta para os filhos, sendo orientados a escreverem sobre seus sentimentos em relação a este contexto que estavam vivenciando no momento. A carta possuía caráter simbólico e não deveria ser entregue aos filhos. Diante do receio do conteúdo emocional de algumas cartas e de seus possíveis usos no Judiciário, posteriormente, decidiu-se que as cartas seriam colocadas na água, a fim de garantir que nenhum participante levasse a carta até o filho.

\section{AVALIANDO OS RESULTADOS: EXPECTATIVA E FEEDBACKS}

Para avaliar o trabalho realizado com os grupos, todos os participantes foram convidados a preencher ficha de avaliação da intervenção entregue no primeiro e no último encontro. As fichas foram elaboradas tendo como suporte o modelo apresentado por Neiva (2010). Ao final de cada encontro os participantes também tinham a possibilidade de oferecer feedbacks diretamente para os integrantes e para as facilitadoras. Os formulários iniciais foram empregados com o objetivo de conhecer a motivação inicial dos participantes e quais as expectativas deles em relação ao trabalho que seria realizado. Os formulários finais, por sua vez, tiveram o intuito de avaliar o trabalho desenvolvido pelas facilitadoras, o preparo e profissionalismo das mesmas, a interação grupal, o aproveita- mento das discussões, bem como o recebimento de sugestões de melhorias.

Por meio dessas avaliações foi possível observar que os participantes que já sabiam que os ex-cônjuges também teriam a oportunidade de participar de um grupo reflexivo listaram a sensibilização do ex-cônjuge durante os encontros como expectativa de que, dessa forma, fosse possível ter mais acesso aos filhos. Os participantes de ambos os grupos citaram que entre as suas expectativas estava a possibilidade de aprendizagem, o crescimento e o amadurecimento pessoal para lidar com o pós-divórcio. Alguns integrantes esperavam que após os encontros ocorresse uma mudança na forma como se relacionavam com os ex-cônjuges no que tange tanto à convivência quanto ao diálogo. Um dos participantes afirmou que entre as suas expectativas estava a de encontrar ajuda para preservar os filhos no contexto do pós-divórcio. A maioria dos participantes afirmou que gostaria de encontrar no grupo um espaço para expor dúvidas, partilhar experiências positivas e/ou negativas e assim ajudar uns aos outros, além de aprender por meio de diferentes vivências.

Com base na avaliação ao final dos encontros, percebeu-se que todos classificaram a intervenção realizada, a interação grupal, o preparo e profissionalismo das facilitadoras como bons ou ótimos. Os temas trabalhados foram classificados como importantes ou muito importantes e o aproveitamento ao longo das discussões foi considerado suficiente ou máximo. No preenchimento da ficha de avaliação da intervenção, os participantes consideraram como aspectos mais importantes ao longo dos encontros: os temas abordados, o acesso a diferentes pontos de vista, a reflexão sobre outras perspectivas, o conhecimento 
adquirido, a convivência com outros participantes e o reconhecimento de vivências semelhantes. Esses feedbacks demonstraram que o trabalho realizado foi ao encontro de muitas das expectativas almejadas pelos participantes citadas anteriormente, além de corresponder à proposta metodológica adotada.

Ao longo dos encontros, os participantes deram muitos feedbacks para as facilitadoras. Dentre eles destaca-se o reconhecimento do trabalho em grupo como um espaço único de escuta e compartilhamento permeado por discussões que os tiravam de sua zona de conforto. Um participante apresentou maior resistência e insatisfação do que os demais ao longo de todos os encontros, por acreditar que apenas a sua ex-esposa deveria estar ali, tendo que lidar com um trabalho em grupo com o qual ele não se identificava. Entretanto, apesar de demonstrar sentimentos negativos em relação ao grupo, ao final de cada encontro ele pedia para que as facilitadoras ligassem para lembrá-lo de estar presente no encontro seguinte, fato que foi percebido pelas facilitadoras como uma tentativa realizada por ele de persistir na continuidade do trabalho em grupo. No decorrer dos encontros esse participante conseguiu se sensibilizar um pouco mais e criar uma relação de confiança para se abrir com outros participantes. Uma das mães participantes reconheceu ao longo dos encontros que seu filho se sentia pressionado por ela após a separação, contribuindo para que ela reavaliasse a postura que estava adotando em relação ao filho no pós-divórcio. Outra mãe que se sentia muito insegura em deixar o filho visitar o pai na casa da madrasta, apesar de ainda enfrentar dificuldades para dialogar com o ex-marido, conseguiu dar início ao processo de superação dessa insegurança, sendo capaz de iniciar um diálogo com a atual esposa de seu ex-cônjuge para facilitar os encontros entre pai e filho.

Em relação ao que poderia ser melhorado, foi sugerido pelos participantes que os grupos contassem com um número maior de pessoas, que ocorressem mais do que quatro encontros e que estes pudessem ser realizados em mais datas e com maiores possibilidades de horários. Todos esses feedbacks demonstraram que o trabalho realizado foi capaz de alcançar o que havia sido proposto. Entretanto, ao longo dos encontros se percebeu uma grande necessidade por parte dos participantes em relatarem suas histórias pessoais e de seus ex-cônjuges com o intuito de se defenderem, ao mesmo tempo em que tentavam desqualificar a outra parte envolvida para os colegas e para as facilitadoras. Essa necessidade de defesa e acusação demonstra que os participantes ainda continuam muito envolvidos numa lógica de conflito, característica do próprio ambiente onde o grupo era ofertado que é um espaço vinculado ao Sistema de Justiça. Essas argumentações eram esperadas, mas também indicam a necessidade de um tempo maior por parte dos participantes para elaborarem essas questões.

Em experiências relatadas na literatura (Rapizo, 2013; Rapizo \& Brito, 2014), a lógica do conflito ou, pelo menos, a sua explicitação durante os encontros é mais diluída quando os grupos se realizam em lugares fora do Sistema Judiciário e também quando os participantes são pessoas que têm questões litigiosas ou não. Portanto, o foco que fica presente pelo local e pela população à qual se destina o grupo tem influência marcante na prevalência de uma determinada lógica. Cabe questionar a própria lógica do conflito, visibilizando e refletindo a respeito do 
que pode promover formas de relação alternativas, mesmo dentro de locais onde se pressupõe o conflito. Desta forma, a utilização dos grupos mostrou-se como um recurso de mobilização do sujeito para esses impasses, mas que não substitui o trabalho desempenhado pelas equipes no atendimento e no acompanhamento dos casos, denotando inclusive a relevância do encaminhamento para psicoterapia quando necessário.

\section{A EXPERIÊNCIA DAS EXTENSIONISTAS ENQUANTO FACILITADORAS DOS GRUPOS REFLEXIVOS COM PAIS E MÃES SEPARADOS}

Esse momento da escrita destina-se ao relato da experiência das extensionistas no decorrer do trabalho desempenhado com os grupos reflexivos, apresentando para este fim os desafios encontrados por elas enquanto facilitadoras, as soluções propostas e os ganhos pessoais e profissionais que advieram do trabalho em questão e também da atuação delas enquanto alunas de extensão. Segundo Beiras e Bronz (2016), o propósito da facilitação é cuidar do processo grupal, o que implica o dever, por parte dos facilitadores, de garantir o funcionamento do grupo reflexivo. Dessa forma, é necessário que o facilitador(a) seja capaz de suprimir situações que possam gerar obstáculos, bem como garantir que o objetivo proposto para a intervenção seja alcançado (Beiras \& Bronz, 2016; Fuks \& Rosas, 2014).

As primeiras facilitadoras do projeto não tiveram acesso prévio a nenhum grupo que trabalhasse com o mesmo tema ou público-alvo, mas ambas possuíam experiências anteriores com grupos reflexivos voltados para públicos diferentes. Além disso, as supervi- sões semanais antes e durante o trabalho, assim como as reflexões realizadas pelas facilitadoras ao término de cada encontro com os grupos, foram consideradas fundamentais para a autoavaliação da dupla a respeito da qualidade do trabalho que estava sendo desempenhado e também para a realização das correções e adaptações necessárias para os encontros subsequentes.

Os materiais utilizados em cada encontro foram um desafio para as facilitadoras ao longo da construção e seleção dos recursos. Desde o início da elaboração dos encontros, direcionou-se parte do tempo para a busca das mídias audiovisuais que seriam aplicadas em cada encontro no intuito de encontrar aquelas que auxiliassem satisfatoriamente na promoção das reflexões propostas. Nesse sentido, muitas buscas foram realizadas por cenas de filmes, séries, propagandas de TV, campanhas nacionais e internacionais, músicas e dinâmicas. Algumas atividades foram criadas pelas próprias facilitadoras em conjunto com a supervisora para alcançar os objetivos propostos.

As maiores dificuldades enfrentadas pelas facilitadoras, contudo, se deram antes do início do trabalho com os grupos, durante a formação e divisão destes. O número de famílias atendidas pelo PROEVI ainda era baixo devido ao início do funcionamento do programa e, dentre as famílias participantes, algumas não estavam aptas a participarem dos grupos por não atenderem aos critérios de seleção já mencionados no tópico de metodologia. Ao final da seleção das famílias, no momento de realizar os convites, as facilitadoras precisaram desempenhar um intenso trabalho para que os participantes compreendessem a intervenção para a qual foram encaminhados. Antes de chegarem ao PROEVI, mui- 
tos participantes já haviam buscado resoluções para as questões familiares, geralmente, pela via judicial. Devido a todo esse processo litigioso, muitos convidados apresentavam resistência em relação à possibilidade de uma nova tentativa. Apesar dos grupos integrarem as atividades do PROEVI, não há obrigatoriedade de participação, porém não se pode desconsiderar o espaço institucional no qual ele é ofertado e seus efeitos para os sujeitos que recebem o convite.

Apesar do atendimento dessas famílias no projeto já estar em andamento, os conflitos e a falta de diálogo presentes no pós-divórcio ainda estavam presentes e contribuíram para a resistência dos participantes em aceitar o convite. Soma-se a dificuldade por parte das facilitadoras em encontrar um horário e dia da semana que atendessem a todos os participantes ou ao menos a maioria destes para constituir o grupo. Nesse sentido, diversos fatores pessoais e de trabalho dos participantes representaram um obstáculo para que fosse possível encontrar datas e horários em comum. Para solucionar essa questão foram disponibilizadas declarações de participação emitidas pelo Ministério Público. Ultrapassados esses desafios, as facilitadoras se depararam com a falta de engajamento por parte de alguns participantes em considerar os encontros como um compromisso. Ligações semanais foram realizadas para auxiliar os participantes a se lembrarem dos encontros quinzenais. Todos os impasses encontrados nesse agendamento eram esperados e perfeitamente compreensíveis em função de todo o desgaste sofrido por esses participantes no pós-divórcio e dos compromissos pessoais/profissionais de cada um.

No decorrer da elaboração e execução dos encontros, as facilitadoras tiveram a oportunidade de desenvolver uma escuta mais atenta, capaz de avaliar a importância de determinadas falas e direcioná-las novamente para o grupo, fomentando as reflexões. O trabalho realizado em dupla proporcionou intervenções complementares que auxiliaram nas novas situações que surgiram. A prática como facilitadoras também permitiu às alunas desenvolverem autoconfiança, autocrítica e criatividade. Os desafios que surgiram demandaram das alunas iniciativa na busca por soluções para os impasses e também resiliência para transpor algumas tentativas frustradas.

No que diz respeito às contribuições da extensão para a formação acadêmica dos alunos, Silva aponta que essa formação vai além da aquisição de conhecimentos técnico-científicos, visto que esses se esvaziam quando não são integrados à realidade (Silva, 2006, p. 121). Desta forma, a participação nessa atividade de extensão permitiu oferecer caminhos que levam à crítica e à autonomia das alunas ao inseri-las, na prática, em problemáticas sociais, além de incentivá-las a prestar serviços à comunidade e buscar por novas soluções em conjunto com o público-alvo.

\section{CONSIDERAÇÕES FINAIS}

Neste artigo buscou-se apresentar em detalhes a construção da atividade ofertada no espaço do Ministério Público, de grupos reflexivos com pais e mães separados que vivenciam pós-divórcio litigioso. Como objetivos da condução dos grupos constam a promoção de conversas e de reflexões acerca de temas como guarda compartilhada, dificuldades enfrentadas no pós-divórcio, pleno exercício da parentalidade e o desenvolvimento de um olhar voltado para os filhos do 
ex-casal que são diretamente afetados pelos conflitos vivenciados pela família após a separação conjugal. No decorrer dos encontros observou-se a necessidade da ampliação do número de encontros para possibilitar maiores debates a respeito da violência doméstica. Essa demanda é decorrente do aumento de casos encaminhados ao PROEVI oriundos da Vara Especializada em Violência Doméstica e Familiar. Foi observada a necessidade de revisão de alguns recursos metodológicos, tais como a Dinâmica dos produtos e a Dinâmica das cartas, pois as propostas almejadas por meio destas encontraram alguns obstáculos na compreensão de sua execução.

Durante as intervenções realizadas, o desgaste sofrido pelas famílias ao longo de todo o processo litigioso foi, frequentemente, observado pela equipe e também relatado pelos próprios participantes. Essa exaustão reflete na aparente incredulidade apresentada por eles ao longo do trabalho no que dizia respeito às possibilidades de melhora na realidade vivenciada naquele momento. Na prática, também foi evidente como a participação e o engajamento de todas as partes são fundamentais para a garantia dos direitos infanto-juvenis no cenário do pós-divórcio, tendo a participação nos grupos de acordo com a equipe psicossocial do PROEVI, auxiliado na redução dos conflitos.

Pais e mães apontaram, em diferentes momentos, que o trabalho realizado em grupo, assim como as demais intervenções realizadas no PROEVI, poderiam ter representado um diferencial ainda maior em suas vidas caso estivessem disponíveis logo após a separação conjugal. Tal afirmação poderia nos levar a pensar na importância do fator tempo no aumento e na cronificação de conflitos que desencadeiam litígios judiciais. Esses relatos evidenciaram a importância não apenas da expansão desse trabalho para outros locais, mas também de sua implementação como política pública em âmbito nacional. Um local relevante para a realização dos grupos reflexivos voltados para o mesmo público seria as Assistências Judiciárias Universitárias presentes nas universidades e faculdades. Muitos pais procuram as assistências para buscar auxílio em relação às questões como guarda dos filhos, pensão alimentícia, abandono afetivo, alienação parental e outras demandas do campo do Direito de Família. Nesse sentido, apresentam-se como uma importante fonte de encaminhamento e mesmo de oferta para as intervenções discutidas, em especial pela possibilidade de propô-las de forma mais preventiva.

Tratando-se da ampliação para outros locais, é importante que essas intervenções sejam oferecidas, principalmente, fora do sistema de justiça, a fim de torná-las acessíveis ao público antes mesmo de sua inserção na perspectiva litigante ainda presente no judiciário. Essa compreensão relaciona-se com uma visão não judicializante da família, que pode encontrar em outras esferas, como a clínica ou a educação, orientações e espaços de troca. Estas afirmações são corroboradas pelo dito anteriormente, referente à importância do contexto onde são realizados os grupos, a diversidade da população participante e ao tempo que se tem para os encontros. Os espaços para conversação sobre o divórcio acabam ficando restritos às terapias tradicionais e aos espaços ligados ao Judiciário. A oferta de outros espaços e trabalhos diferenciados, reflexivos e mais preventivos poderia auxiliar nos percursos das separações, trazendo benefícios aos envolvidos no âmbito das suas relações pós-separação. 
Como ilustração desta afirmação, atualmente o projeto de Extensão Universitária na Universidade do Estado do Rio de Janeiro intitulado Espaços de Conversa sobre Divórcio vem realizando encontros com pessoas que passaram pelo divórcio e se interessam em conversar sobre o tema. Comparecem aos encontros pais, mães e filhos com mais de 18 anos de famílias diversas. Utilizando metodologia reflexiva, tais encontros têm se mostrado ricos em possibilitar aos participantes uma visão mais ampla sobre separações, relações familiares e outros temas pertinentes ao tema do projeto. Funciona dentro de uma lógica menos ligada ao conflito e mais ligada ao interesse na troca e reflexão sobre o tema. A diversidade de contextos onde podem ser realizados os encontros possibilita a diversidade de abordagens, não excludentes entre si, mas complementares e podendo alcançar pessoas em diferentes situações e momentos do divórcio.

O PROEVI encontrou no trabalho realizado com os grupos reflexivos desenvolvidos pela extensão a possibilidade de complementar sua estrutura e oferecer uma modalidade diferenciada para a realização da abordagem com essas famílias. Os benefícios dos atendimentos individuais, os acompanhamentos de visitas realizados e a promoção de diálogo entre as partes foram evidenciados ao longo dos encontros. Ao passo que a maior abertura dos genitores para dialogar e encontrar saídas para os conflitos, a ampliação da compreensão dos temas que permeiam as vivências dos participantes e os efeitos de se ter acesso às vivências tão distintas e ao mesmo tempo tão semelhantes às suas também foram percebidos ao longo dos trabalhos desenvolvidos fora dos grupos.

Entende-se que é necessário e fundamental que esses pais e mães tenham acesso a um espaço de fala, de escuta e de reflexão fora do âmbito judicial e que na medida em que compartilham suas dificuldades e medos, possam ter também acesso a outras vivências. Essa troca de experiências torna possível encontrar soluções para problemas comuns àqueles que desfazem o vínculo conjugal e permite aos participantes proporem soluções com base em suas próprias experiências. Dessa forma, acreditamos que os grupos reflexivos têm se mostrado um dispositivo importante para gerar novos entendimentos a respeito do contexto das famílias, promover transformações e oferecer suporte a essas famílias.

\section{REFERÊNCIAS}

Acosta, F: Andradade, A., \& Bronz, A. (2004). Conversas homem a homem: grupo reflexivo de gênero: metodologia. Instituto Noos de Pesquisas Sistêmicas e Desenvolvimento de Redes Sociais.

Badinter E. (1985). Um amor conquistado: o mito do amor materno ( $3^{\mathrm{a}}$ ed.). Rio de Janeiro: Nova Fronteira.

Beiras, A. \& Bronz, A. (2016). Metodologia de grupos reflexivos de gênero. Rio de Janeiro: Instituto Noos.

Brito, L. M. T. (2001). Impasses na condição da guarda e da visitação-o palco da discórdia. Associação de Pais e Mães Separados- APASE. Recuperado de http://www.apase.org. br/91009-impasses.htm

Brito, L. M. T. (2002). Impasses na condição da guarda e da visitação: o palco da discórdia. In R. C. Pereira (Org.), Família e cidadania - o novo $C C B$ e a vacatio legis (p. 10). Belo Horizonte: IBDFAM/Del Rey.

Brito, L. M. T. (2007) Família pós-divórcio: a visão dos filhos. Psicologia: Ciência e Profissão, 27(1), 38. 
Brito, L. M. T., Cardoso, A. R., \& Oliveira, J. D. G. (2010). Debates entre pais e mães divorciados: um trabalho com grupos. Psicologia: Ciência e Profissão, 30(4), 810-823.

Britz, I., Didonet, M. , Lustosa, V. , Barbosa, W. (produtores) Alvarenga, J. (2009) Divã [filme-vídeo]. Brasil. Globo Filmes.

Cardoso, F. S. \& Brito, L. M. T. (2015). Possíveis impasses da Lei Maria da Penha à convivência parental. Estudos e Pesquisas em Psicologia, 15(2), 529-546.

Falıão, C. F. A. \& Souza, L. C (2013). Eu me lembro. In Monomania [CD]. São Paulo: Casa Byington.

Ficarra, G. \& Requa, J. (Dir.). (2011). Amor a toda prova [filme-vídeo]. CA, US: Warner Bros Picture.

Fuks, S. \& Rosas, E. V. (2014) A FSPC (Facilitação Sistêmica de Processos Coletivos) em grupos, organizações e comunidades. Nova Perspectiva Sistêmica, 23(48), 8-23. Recuperado de: http://revistanps.com.br/index. php/nps/article/view/47/29

Garcia, M. L. T. \& Tassara, E. (2003). Problemas no casamento: uma análise qualitativa. Estudos de Psicologia, 8(1), 127-133.

Neiva, K. M. C. (2010). O que é intervenção psicossocial. In Intervenção psicossocial: aspectos teóricos, metodológicos e experiências práticas (pp. 11-58). São Paulo: Vetor.

Oliveira, C. F. B. \& Brito, L. M. T. (2013). Judicialização da vida na contemporaneidade. Psicologia: Ciência e Profissão, 33(n. spe.), 7889. Recuperado de http://www. scielo.br/scielo.php?pid=S1414$-98932013000500009 \&$ script $=$ sci abstract\&tlng $=$ pt Pereira, C. V. (2013). Psicologia Jurídica e Abordagem Gestáltica - Um Encontro nas Varas de Família. Rio de Janeiro: Juruá.
Rapizo, R. (2012). Construindo espaços de diálogo com pais, mães e adolescentes nos contextos de divórcio. In L. M. T. Brito (Org.), Escuta de crianças e adolescentes: reflexões, sentidos e práticas (pp. 119-153, 1a ed.). Rio de Janeiro: EDUERJ.

Rapizo, R., \& Brito, L. M. T. (2014). Espaço de conversas sobre divórcio: a diferença de posicionamento como recurso de transformação. Nova Perspectiva Sistêmica, 50, 32-49.

Sarriera, J. C., Silva, M. A., Pizzinato, A.s Zago, C.s \& Meira, P. (2000). Intervenção psicossocial e algumas questões éticas e técnicas. In J. C. Sarriera (Coord.), Psicologia comunitária: estudos atuais (pp. 25-44). Porto Alegre: Sulina.

Silva, M. S. (2006). Extensão universitária e formação profissional: avaliação da experiência das ciências biológicas na Universidade Federal do Pernambuco. Estudos em Avaliação Educacional, 17(33), 119-135.

Soares, L. C. E. C (2013). Padrastos e madrastas: construindo seus lugares nas famílias recasadas. Tese de Doutorado em Psicologia Social, Instituto de Psicologia, Universidade do Estado do Rio de Janeiro, RJ. (não publicada)

Soares, L. C. E. C. (2015). Pais e Mães Recasados - Vivências e Desafios no Fogo Cruzado das Relações Familiares. Curitiba: Juruá.

Sousa, A. M. (2010). Síndrome da alienação parental: um novo tema nos juízos de família. São Paulo: Cortez.

Yacubian, J. \& Neto, F. L. (2001). Psicoeducação familiar. Família, Saúde e Desenvolvimento, 3(2), 98-108. 
É psicóloga graduada pela Universidade Federal de Minas Gerais. Ex-aluna voluntária do projeto de extensão "Diálogos familiares em grupo: construindo caminhos para a convivência familiar após a separação conjugal".

E-mail: 1slucianaoliveira@gmail.com

\section{LUDIMILA REGINA ROSENTHAL CAETANO DE OLIVEIRA}

É psicóloga graduada pela Universidade Federal de Minas Gerais.

E-mail: ludimila.rosenthal@gmail.com

\section{LAURA CRISTINA EIRAS COELHO SOARES}

É docente de Psicologia do Departamento de Psicologia da Faculdade de Filosofia e Ciências Humanas e do Programa de Pós-Graduação em Psicologia da UFMG. Doutora e mestre em Psicologia Social pela UERJ.

E-mail: laurasoarespsi@yahoo.com.br

\section{ROSANA LAZARO RAPIZO}

É professora adjunta do curso de Psicologia da Universidade Estadual do Rio de Janeiro. Doutora em Psicologia Social e mestre em Psicologia Clínica pela UERJ.

E-mail: rosanarapizo@gmail.com 